\title{
Brief tobacco cessation interventions: Practices, opinions, and attitudes of healthcare professionals
}

\author{
Joseph Grech ${ }^{1,2,3}$, Roberta Sammut ${ }^{2}$, Mariella B. Buontempo ${ }^{3}$, Pauline Vassallo ${ }^{3}$, Neville Calleja ${ }^{4}$
}

\begin{abstract}
INTRODUCTION Although brief smoking cessation interventions that follow the 5As algorithm (Ask, Advise, Assess, Assist, Arrange) can trigger smokers to quit, routine delivery remains low in Europe. This study aimed to identify the extent of smoking cessation practices of healthcare professionals interested in tobacco cessation, and their opinions and attitudes.

METHODS A quantitative, cross-sectional survey design was adopted. Healthcare professionals $(n=133)$ who attended one of ten training sessions on brief interventions for smoking cessation, held every month between September 2018 and June 2019 in Malta, were recruited. Univariate logistic regression and non-parametric tests were carried out to identify associations by participants' characteristics. Potential confounders were ruled out following multivariate analyses.

RESULTS Most participants were female nurses who had never smoked. While most professionals reportedly asked (76.3\%), advised (83.5\%) and assessed (70.5\%) patients for cessation, fewer provided assistance (40.9\%) and arranged followup $(24.2 \%)$. Compared to other participants, doctors were more likely to have counselled patients over the previous week. Most professionals were favourably disposed towards counselling patients to quit, however, they claimed they had insufficient time to do so. Although most found it difficult to get clients to quit, former smokers were more likely to disagree when compared to those who never smoked (OR=6.86; 95\% CI: 2.17-21.71; $\mathrm{p}=0.001)$.

CONCLUSIONS While more initiatives to train healthcare professionals in providing smoking cessation interventions are recommended, lack of sufficient time, being an organisational barrier, requires healthcare management exploration and action. Given that former smokers were more confident in helping patients quit, engaging them in training activities would be of added value.
\end{abstract}

\section{AFFILIATION}

1 Institute of Applied Sciences, Malta College of Arts, Science and Technology, Paola, Malta 2 Department of Nursing, Faculty of Health Sciences, University of Malta, Msida, Malta

3 Department for Health Regulation, Health Promotion and Disease Prevention Directorate, Ministry for Health, Pietà, Malta 4 Department for Policy in Health, Directorate for Health Information and Research, Ministry for Health, Pietà, Malta

CORRESPONDENCE TO Joseph Grech. Institute of Applied Sciences, Malta College of Arts, Science and Technology, Paola, PLA9032, Malta. E-mail: joseph. grech@mcast.edu.mt

\section{KEYWORDS}

smoking cessation, attitudes, healthcare providers, continuing education

Received: 20 April 2020

Revised: 30 June 2020

Accepted: 13 July 2020

\section{INTRODUCTION}

The World Health Organisation (WHO) European Region reports the highest prevalence rate of tobacco use $^{1}$, where tobacco is responsible for 0.7 million deaths each year ${ }^{2}$. Smokers who quit can significantly reduce their risk of developing smoking-attributable diseases ${ }^{3}$. Additionally, smoking cessation can reduce all-cause mortality risk, particularly that from cardiovascular and respiratory diseases, and tobacco- related cancers ${ }^{4}$.

Article 14 of the WHO Framework Convention on Tobacco Control (WHO FCTC) stipulates that members should ensure that all tobacco users are identified and provided with at least brief advice during a health interaction ${ }^{5}$. Screening for tobacco use and subsequent personalised brief advice often proves to be opportunistic, as the identified smoker might not be seeking tobacco cessation support ${ }^{3,6}$. 
As tobacco dependence has been classified as a disease ${ }^{6-9}$, every healthcare professional has the duty to diagnose and treat the patient just as he/she would do for other chronic diseases ${ }^{6}$.

The 5As (Ask, Advise, Assess, Assist, Arrange) algorithm summarises all the activities that healthcare professionals can do in order to carry out brief smoking cessation interventions $\mathrm{s}^{6,10}$. These five strategies are about: asking all patients about smoking status; advising those who smoke to quit; assessing readiness to quit; assisting them with making a quit plan; and arranging follow-up. Receipt of the 5As was found to be significantly associated with the increased use of recommended counselling and cessation medication ${ }^{11}$, and with greater patient satisfaction ${ }^{12}$. Receipt of 'ask'13 and the latter four of the $5 \mathrm{As}^{14}$ was associated with an increased likelihood of a quit attempt. Nonetheless, patients' recall of brief smoking cessation assistance was found to be low in some European countries ${ }^{13,15,16}$, warranting the need for investigation of the bigger picture.

Although the prevalence of tobacco use in Europe appears to be decreasing slowly ${ }^{17}$, in Malta the smoking prevalence rate has remained practically unchanged at $24 \%^{2}$. Malta, like some other European countries, lacks national tobacco cessation clinical guidelines ${ }^{3}$, which healthcare professionals can follow, leaving much to guess as to what is happening in practice. Consequently, this study aimed to:

- Identify the extent of tobacco cessation practices of healthcare professionals interested in tobacco cessation;

- Investigate the participants' opinions about counselling patients to stop, and examine their attitudes about healthcare professionals and smoking, and their role in tobacco control; and

- Identify any differences by gender, smoking status, and other professional characteristics.

\section{METHODS}

\section{Study design and measures}

A descriptive cross-sectional survey was carried out. The widely used and psychometrically sound instrument 'Nurses Helping Smokers Quit' was utilised $^{18}$. The original questionnaire had a very good level of reliability $(\alpha=0.92)^{19}$. It was adapted, tested for validity by experts in nursing in tobacco control and re-tested for reliability (93\% of the kappa values were $>0.7)^{18,20}$. In this study, all questions/statements were directed to healthcare professionals instead of nurses, while participants were asked to indicate their profession. Otherwise, the tool was left as originally set:

- Assessing information on gender, professional characteristics and smoking status;

- Looking at frequency (always, usually, sometimes, rarely, or never) of delivery of ten listed tobacco cessation interventions and identifying the estimated number of patients helped during the previous week (ranging: none, $1-2,3-5,>5$ );

- Assessing agreement to eight positively worded and five negatively worded opinions about counselling patients to quit smoking by means of a Likert scale (strongly disagree, disagree, neutral, agree, and strongly agree); and

- Identifying attitudes about healthcare professionals and smoking, and their role in tobacco control (three positively worded attitudes, to which participants rated their agreement, and two linear scale questions, which participants rated from 'least important' to 'most important') ${ }^{18}$.

To ensure its validity for distribution amongst healthcare professionals in Malta, the questionnaire was assessed for face validity by a doctor, a nurse, a pharmacist and an allied healthcare professional, and by two public health consultants. No changes were required.

\section{Study participants}

Healthcare professionals, who attended one of ten training sessions on brief interventions for smoking cessation, held every month between September 2018 and June 2019 in Malta, were included as potential study participants. Several strategies (mainly mailshots and advertisements) were used for recruiting healthcare professionals, who were interested in tobacco cessation, to these educational sessions. In all, 150 healthcare professionals attended these training sessions and were provided with the questionnaire, which they filled in before the commencement of the training session.

In order to be eligible to this study, they had to be health workers who provided direct patient care to adult patients (aged $\geq 18$ years) during a typical working day. Respondents who were health workers with no direct patient care, or who cared only for paediatric patients, were excluded.

This study was part of a training project on brief 
smoking cessation interventions for healthcare professionals in the public service, held by the Health Promotion and Disease Prevention Directorate within the Department for Health Regulation/ Superintendence of Public Health, Ministry for Health, Malta. An information letter was attached to each questionnaire, providing details on the aims of the audit and the training session. It also invited participants to write their email address, which was the sole personal identifier, to be used for longterm evaluation of the training project. Filling in the questionnaire was voluntary and not a requirement to attend the educational session. Participants were informed that the Directorate abided by Article 27 (a)(i) of the Public Health Act ${ }^{21}$, the Data Protection $\mathrm{Act}^{22}$, and the General Data Protection Regulation (EU) $2016 / 679^{23}$ for the processing of personal data. Return of a completed questionnaire implied consent. All responses were kept confidential and later anonymised through the generation of a unique code identifier. No ethical issues were envisaged.

\section{Statistical analysis}

All analyses were done using IBM SPSS Statistics Version 26. Descriptive statistics (frequencies, percentages, means with standard deviations) were used to characterise the sample and study variables. As for previous studies ${ }^{18,20}$, we defined consistency of performing tobacco cessation interventions by collapsing 'always/usually'. Similarly, agreement to positively worded opinions and attitudes about counselling patients was denoted as "strongly agree/ agree', while disagreement to negatively worded opinions and attitudes was defined as 'strongly disagree/disagree'. Univariate logistic regression was carried out to identify any significant associations in these revised, now binary variables by the independent variables, taking note of within group differences with their respective odds ratio (OR), 95\% confidence intervals (CI) and p-values. On the other hand, given that some groups of participants were quite small, non-parametric tests were used to identify differences in the other non-binary dependent variables and for associations by years of experience. The MannWhitney U test was used to assess the relationship between years of experience and the binary variables. With regard to the estimated number of patients helped in the past week, Fisher's exact test was used; whereas for years of experience the Kruskal Wallis test was used. The Kruskal Wallis test (and subsequently Dunn's pairwise tests with adjustment using the Bonferroni correction) and the Mann-Whitney U test were also utilised to identify associations for the two linear scale questions by the independent variables, except for years of experience, where the Pearson correlation coefficient was computed. Where significant differences were observed in more than one independent variable, a multivariate analysis was conducted to identify and rule out any confounder. A $\mathrm{p} \leq 0.05$ was considered as the threshold required for all statistically significant associations.

\section{RESULTS}

\section{Participants' characteristics}

All (150) participants completed the questionnaire. After excluding those who did not provide direct patient care to adult patients, 133 healthcare professionals were found to be eligible and were included in data analysis. Participants' characteristics are displayed in Table 1. Most participants were female nurses, who never smoked, and who worked in hospital settings. Mean years of experience were 14.9 \pm 12.7 . Only 11 participants had received training in smoking cessation within the past 24 months.

\section{Delivery of tobacco cessation interventions to patients}

As displayed in Table 2, whereas most participants consistently (always/usually) asked (76.3\%; $\mathrm{n}=100)$, advised $(83.5 \% ; \mathrm{n}=111)$, and assessed $(70.5 \% ; \mathrm{n}=93)$ patients for tobacco cessation, fewer participants assisted $(40.9 \% ; n=54)$ and arranged follow-up $(24.2 \% ; \mathrm{n}=31)$. Moreover, few participants routinely carried out the other listed tobacco cessation interventions, except for "recommend to patients and family members the importance of creating a smoke-free home environment' $(65.7 \% ; n=86)$. Most participants (46.6\%; $\mathrm{n}=62$ ) had counselled 1-2 patients over the previous week.

\section{Opinions about counselling patients to quit smoking and attitudes about healthcare professionals and smoking, and their role in tobacco control}

Table 3 shows the responses to the 13 opinions about counselling patients to quit. Most respondents 
Table 1. Gender, smoking status and professional characteristics

\begin{tabular}{|c|c|c|c|}
\hline \multirow[t]{2}{*}{ Variable } & \multirow[t]{2}{*}{ Response } & \multicolumn{2}{|c|}{ Value } \\
\hline & & $n$ & $\%$ \\
\hline \multirow[t]{2}{*}{ Gender } & Female & 87 & 65.4 \\
\hline & Male & 46 & 34.6 \\
\hline \multirow[t]{3}{*}{ Smoking status ${ }^{\mathrm{a}}$} & Never smoker & 105 & 78.9 \\
\hline & Former smoker & 15 & 11.3 \\
\hline & Current smoker & 13 & 9.8 \\
\hline \multirow[t]{5}{*}{ Profession } & Nurse & 64 & 48.1 \\
\hline & Doctor & 40 & 30.1 \\
\hline & Allied health ${ }^{b}$ & 23 & 17.3 \\
\hline & Pharmacist & 4 & 3.0 \\
\hline & Other & 2 & 1.5 \\
\hline \multirow[t]{3}{*}{ Place of work } & Hospital & 62 & 46.6 \\
\hline & Primary healthcare & 39 & 29.3 \\
\hline & Long-term care & 32 & 24.1 \\
\hline \multirow[t]{3}{*}{ Highest qualification } & Master's or Doctorate & 47 & 36.4 \\
\hline & Undergraduate degree & 43 & 33.3 \\
\hline & Diploma & 39 & 30.2 \\
\hline \multirow{2}{*}{$\begin{array}{l}\text { Training in smoking } \\
\text { cessation within the } \\
\text { past } 24 \text { months }\end{array}$} & No & 118 & 91.5 \\
\hline & Yes & 11 & 8.5 \\
\hline \multirow[t]{5}{*}{ Training location } & Mater Dei Hospital & 65 & 48.9 \\
\hline & $\begin{array}{l}\text { Primary Health Care } \\
\text { Department }\end{array}$ & 36 & 27.1 \\
\hline & $\begin{array}{l}\text { Malta Union of } \\
\text { Midwives and Nurses }\end{array}$ & 25 & 18.8 \\
\hline & Gozo General Hospital & 7 & 5.3 \\
\hline & & Mean & SD \\
\hline Participants per month & & 13.3 & 5.2 \\
\hline Years of experience & & 14.9 & 12.7 \\
\hline
\end{tabular}

a Smoking status was defined as follows: former smoker - having ever smoked 100 or more cigarettes in life; never smoker - having never smoked; and current smoker - having ever smoked 100 or more cigarettes in life and currently smoking. b Allied healthcare professionals included professionals complementary to medicine as listed under the Health Care Professions $\mathrm{Act}^{37}$ and under the Allied Health Services Directorate $^{38}$ (i.e. nutritionists, occupational therapists, podiatrists, speech language pathologists and physiotherapists, psychologists/psychologist-assistants and social workers/assistants). c Healthcare providers who did not specify their profession.

agreed (strongly agree/agree) to the first eight positive opinions (ranked in a descending order of agreement), except for 'asking patients about smoking increases the likelihood that they will quit', where only 48 participants agreed (37\%). Most disagreed (strongly disagree/disagree) to the other negatively worded statements (ranked in a descending order of disagreement) with the exception of 'it is difficult for me to get people to quit smoking', and 'I have insufficient time to counsel patients about quitting smoking' (18.2\%, $\mathrm{n}=24$; and $39.3 \%, \mathrm{n}=51$; respectively). Almost all participants $(93.1 \% ; n=121)$ agreed that they need more training to help patients to quit smoking.

As evidenced in Table 4, the majority of the respondents agreed with the attitudes presented or rated them as important. Again, the need for additional training and skills in tobacco control was highlighted by almost all participants (94.8\%; $\mathrm{n}=126)$.

\section{Differences by gender, smoking status, and professional characteristics}

Following the multivariate analyses, where confounders were identified, the variables that remained statistically significant by personal and professional characteristics (Supplementary file, Tables S1-S3), were further analysed for associations within the groups.

\section{Gender}

While females were less likely to routinely give advice, when compared to males $(\mathrm{OR}=0.07$; $95 \% \mathrm{CI}$ : $0.01-0.54$; adjusted $\mathrm{p}=0.010$ ), they were more likely to report having sufficient time to counsel patients $(\mathrm{OR}=4.11 ; 95 \%$ CI: 1.77-9.57; adjusted $\mathrm{p}=0.003)$.

\section{Smoking status}

Smokers were less likely to agree that "providing tobacco cessation counselling is important to our hospital/service, even if only a few patients quit' $(\mathrm{OR}=0.12 ; 95 \%$ CI: $0.02-0.62 ; \mathrm{p}=0.012)$ and 'I have an obligation to advise patients on the health risk associated with tobacco use' (OR=0.09; 95\% CI: 0.02$0.51 ; \mathrm{p}=0.006)$ when compared to never smokers. On the other hand, former smokers were more likely to disagree to 'it is difficult for me to get people to quit smoking' ( $\mathrm{OR}=6.86$; 95\% CI: 2.17-21.71; $\mathrm{p}=0.001$ ), when compared to those who never smoked.

\section{Profession}

Compared to doctors, both pharmacists $(\mathrm{OR}=0.27$; 95\% CI: $0.01-0.35 ; \mathrm{p}=0.006)$ and nurses $(\mathrm{OR}=0.17$; 95\% CI: $0.05-0.62 ; \mathrm{p}=0.007)$ were less likely to 
Table 2. Delivery of tobacco cessation interventions to patients

\begin{tabular}{|c|c|c|c|c|c|c|}
\hline \multirow[t]{2}{*}{ Tobacco cessation interventions } & \multicolumn{5}{|c|}{ Frequency of delivery (\%) } & \multirow[t]{2}{*}{$n$} \\
\hline & Always & Usually & Sometimes & Rarely & Never & \\
\hline Ask about patient's smoking/tobacco use & 36.6 & 39.7 & 16.0 & 3.8 & 3.8 & 131 \\
\hline Advise a patient to quit smoking & 51.9 & 31.6 & 10.5 & 4.5 & 1.5 & 133 \\
\hline Assess if patients are interested in stopping smoking & 39.4 & 31.1 & 20.5 & 6.8 & 2.3 & 132 \\
\hline Assist a patient with smoking cessation & 19.7 & 21.2 & 30.3 & 20.5 & 8.3 & 132 \\
\hline Arrange smoking cessation follow-up & 9.4 & 14.8 & 28.9 & 25.0 & 21.9 & 128 \\
\hline $\begin{array}{l}\text { Recommend the use of a telephone quitline for smoking } \\
\text { cessation }\end{array}$ & 6.9 & 17.7 & 24.6 & 24.6 & 26.2 & 130 \\
\hline $\begin{array}{l}\text { Refer a patient to tobacco cessation resources (clinics, } \\
\text { counselling etc.) in the community }\end{array}$ & 12.9 & 22.0 & 28.0 & 22.7 & 14.4 & 132 \\
\hline Provide recommendations for tobacco cessation medications & 10.0 & 20.8 & 25.4 & 17.7 & 26.2 & 130 \\
\hline $\begin{array}{l}\text { Review barriers to quitting with patients who are unwilling } \\
\text { to make a quit attempt }\end{array}$ & 9.2 & 28.2 & 33.6 & 18.3 & 10.7 & 131 \\
\hline \multirow{3}{*}{$\begin{array}{l}\text { Recommend to patients and family members the } \\
\text { importance of creating a smoke-free home environment } \\
\text { after leaving the hospital }\end{array}$} & 31.3 & 34.3 & 18.3 & 7.6 & 8.4 & 131 \\
\hline & \multicolumn{4}{|c|}{ Number of patients counselled (\%) } & & \\
\hline & 0 & $1-2$ & $3-5$ & $>5$ & & $n$ \\
\hline Counsel patients for smoking cessation over the past week & 27.5 & 47.3 & 16.8 & 8.4 & & 131 \\
\hline
\end{tabular}

Table 3. Rating of opinions about counselling patients to quit smoking

\begin{tabular}{|c|c|c|c|c|c|c|}
\hline \multirow[t]{2}{*}{ Opinions about counselling patients to quit smoking } & \multicolumn{5}{|c|}{ Rating (\%) } & \multirow[t]{2}{*}{$n$} \\
\hline & $\begin{array}{l}\text { Strongly } \\
\text { disagree }\end{array}$ & Disagree & Neutral & Agree & $\begin{array}{l}\text { Strongly } \\
\text { agree }\end{array}$ & \\
\hline $\begin{array}{l}\text { I have an obligation to advise patients on the health risks } \\
\text { associated with tobacco use }\end{array}$ & 0 & 3.1 & 2.3 & 24.4 & 70.2 & 131 \\
\hline $\begin{array}{l}\text { Providing tobacco cessation counselling is important to our } \\
\text { hospital even if only a few patients quit }\end{array}$ & 1.5 & 0 & 4.6 & 35.9 & 58.0 & 131 \\
\hline I need more training to help patients quit smoking & 0 & 2.3 & 4.6 & 47.7 & 45.4 & 130 \\
\hline $\begin{array}{l}\text { As a healthcare professional, I can play an important role in } \\
\text { helping patients quit }\end{array}$ & 0.8 & 3.9 & 5.4 & 38.8 & 51.2 & 129 \\
\hline I should take a more active role in helping patients to quit smoking & 1.5 & 4.6 & 13.7 & 58.8 & 21.4 & 131 \\
\hline $\begin{array}{l}\text { Patients appreciate it when I provide advice about quitting } \\
\text { smoking }\end{array}$ & 2.3 & 5.3 & 25.2 & 52.7 & 14.5 & 131 \\
\hline $\begin{array}{l}\text { Discussing smoking cessation improves my relationship with } \\
\text { patients }\end{array}$ & 0.8 & 4.6 & 36.6 & 51.1 & 6.9 & 131 \\
\hline $\begin{array}{l}\text { Asking patients about smoking increases the likelihood that } \\
\text { they will quit }\end{array}$ & 5.4 & 27.7 & 30.0 & 30.8 & 6.2 & 130 \\
\hline I feel uncomfortable asking patients whether they smoke & 56.2 & 33.1 & 4.6 & 1.5 & 4.6 & 130 \\
\hline $\begin{array}{l}\text { Counselling patient about quitting is not an efficient use of } \\
\text { my time }\end{array}$ & 28.2 & 49.6 & 11.5 & 8.4 & 2.3 & 131 \\
\hline Patients will be offended if I inquire about their smoking status & 32.8 & 38.2 & 19.1 & 8.4 & 1.5 & 131 \\
\hline $\begin{array}{l}\text { I have insufficient time to counsel patients about quitting } \\
\text { smoking }\end{array}$ & 13.1 & 26.2 & 26.2 & 26.2 & 8.5 & 130 \\
\hline It is difficult for me to get people to quit smoking & 3.0 & 15.2 & 34.8 & 36.4 & 10.6 & 132 \\
\hline
\end{tabular}


Table 4. Rating of attitudes about healthcare professionals and smoking and their role in tobacco control

\begin{tabular}{|c|c|c|c|c|c|c|c|c|}
\hline \multirow{2}{*}{$\begin{array}{l}\text { Attitudes and beliefs about healthcare professionals } \\
\text { and smoking and their role in tobacco control }\end{array}$} & \multirow[b]{2}{*}{$\begin{array}{l}\text { Strongly } \\
\text { disagree }\end{array}$} & \multicolumn{3}{|c|}{ Rating (\%) } & \multirow{2}{*}{\multicolumn{2}{|c|}{$\begin{array}{l}\text { Strongly } \\
\text { agree }\end{array}$}} & & \\
\hline & & Disagree & Neutral & Agree & & & & \\
\hline $\begin{array}{l}\text { Healthcare professionals need additional training/ } \\
\text { skills in tobacco control }\end{array}$ & 3.0 & 0.8 & 1.5 & 27.1 & 67.7 & 133 & & \\
\hline $\begin{array}{l}\text { Healthcare professionals should be involved in } \\
\text { actively helping patients to stop smoking }\end{array}$ & 2.3 & 0.8 & 3.0 & 33.8 & 60.2 & 133 & & \\
\hline \multirow{2}{*}{$\begin{array}{l}\text { Healthcare professionals should set a good example } \\
\text { by not smoking }\end{array}$} & 2.3 & 3.8 & 9.8 & 24.8 & 59.4 & 133 & & \\
\hline & $\begin{array}{l}\text { Least } \\
\text { important } \\
\text { (1) }\end{array}$ & (2) & (3) & (4) & $\begin{array}{l}\text { Most } \\
\text { important } \\
\text { (5) }\end{array}$ & $n$ & Mean & SD \\
\hline $\begin{array}{l}\text { Compared to other disease prevention activities } \\
\text { (e.g. nutrition, exercise etc.), how important is it for } \\
\text { healthcare professionals to be involved in tobacco } \\
\text { control activities? }\end{array}$ & 0 & 0.8 & 10.6 & 26.5 & 62.1 & 132 & 4.5 & 0.72 \\
\hline $\begin{array}{l}\text { How important is it for healthcare professionals to be } \\
\text { involved in tobacco control activities? }\end{array}$ & 0 & 1.5 & 9.1 & 30.3 & 59.1 & 132 & 4.47 & 0.73 \\
\hline
\end{tabular}

consistently ask about tobacco use. Also, compared to doctors, pharmacists (OR=0.11; 95\% CI: $0.01-$ $1.02 ; \mathrm{p}=0.052)$ and allied healthcare professionals $(\mathrm{OR}=0.21 ; 95 \%$ CI: $0.05-0.80 ; \mathrm{p}=0.022)$ were less likely to provide advice. A Fisher's exact test showed that out of the professionals who had counselled 3-5 patients or $>5$ patients over the previous week, the majority, $59.1 \%$ (13 out of 22 ) and $45.5 \%$ (5 out of 11 ) were doctors (adjusted $\mathrm{p}=0.007$ ). Compared to doctors, nurses ( $\mathrm{OR}=0.29$; $95 \%$ CI: $0.12-0.66$; $\mathrm{p}=0.004)$ and allied healthcare professionals (OR=0.27; 95\% CI: 0.09-0.84; $\mathrm{p}=0.024)$ were less likely to agree that 'asking patients about smoking increases the likelihood that they will quit'. On the other hand, allied healthcare professionals were more likely to report having sufficient time to counsel patients (OR=8.50; 95\% CI: 2.63-27.50; $\mathrm{p}<0.001)$ compared to doctors.

\section{Years of experience}

Use of the Mann-Whitney U test showed that consistent delivery of tobacco cessation interventions was associated with higher mean years of experience. Participants who were more likely to 'advise' ( $\mathrm{U}=738.0$; mean years of experience $16.11 \pm 13.13$; adjusted $\mathrm{p}=0.020)$, 'assess' $(\mathrm{U}=812.50 ; 18.03 \pm$ 12.94; $\mathrm{p}<0.001)$, 'assist' $(\mathrm{U}=1402.0 ; 18.79 \pm 13.18$; $\mathrm{p}=0.003)$, 'arrange' $(\mathrm{U}=827.50 ; 20.80 \pm 12.63$; $\mathrm{p}=0.001$ ), 'recommend the use of a telephone quitline' $(\mathrm{U}=868.0 ; 21.13 \pm 12.80$; adjusted $\mathrm{p}=0.009)$, 'refer a patient to tobacco cessation resources' ( $\mathrm{U}=1224.0$; $19.84 \pm 12.56$; adjusted $\mathrm{p}<0.001$ ), and 'recommend to patients and family members the importance of creating a smoke-free home environment after leaving the hospital' $(\mathrm{U}=1317.50 ; 16.85 \pm 12.97 ; \mathrm{p}=0.008)$ had higher mean years of experience. Those who agreed that 'healthcare professionals should set a good example by not smoking' were more likely to have more years of experience ( $\mathrm{U}=1450.0 ; 15.97 \pm 12.98$; $\mathrm{p}=0.009$ ). Nonetheless, experienced professionals were more likely to find that counselling patients is not an efficient use of their time ( $U=1976.0 ; 20.93 \pm$ 12.30; adjusted $\mathrm{p}=0.018$ ).

\section{Place of work}

When comparing the consistent delivery of tobacco cessation interventions within different healthcare settings, it was noted that asking about tobacco use was less likely to be carried out by those working in residential care settings ( $\mathrm{OR}=0.07 ; 95 \% \mathrm{CI}$ : $0.02-0.20 ; \mathrm{p}<0.001)$. Also, those working within primary healthcare settings $(\mathrm{OR}=0.28 ; 95 \% \mathrm{CI}$ : $0.11-0.72 ; \mathrm{p}=0.009)$ and residential care settings ( $\mathrm{OR}=0.28 ; 95 \%$ CI: $0.10-0.79 ; \mathrm{p}=0.015)$ were less likely to routinely provide recommendations for medications. Nonetheless, those working in primary 
healthcare settings were more likely to refer patients to tobacco cessation resources within the community $(\mathrm{OR}=2.33 ; 95 \%$ CI: $1.02-5.33 ; \mathrm{p}=0.046)$. Healthcare professionals working in residential care settings were less likely to agree that 'as a healthcare professional I can play an important role in helping patients quit' ( $\mathrm{OR}=0.18$; 95\% CI: 0.05-0.63; $\mathrm{p}=0.007)$ and 'I should take a more active role in helping patients to quit smoking' $(\mathrm{OR}=0.31 ; 95 \% \mathrm{CI}: 0.11-0.86 ; \mathrm{p}=0.024)$ compared to those working in hospital settings. Moreover, those working in residential care settings were less likely to see counselling as an efficient use of their time ( $\mathrm{OR}=0.14 ; 95 \%$ CI: $0.05-0.40 ; \mathrm{p}<0.001)$ and less likely to think that patients would find it acceptable to be asked about their smoking status ( OR $=0.07 ; 95 \%$ CI: $0.02-0.20 ; \mathrm{p}<0.001)$, when compared to those working in hospital settings. Use of the Kruskal Wallis test showed that the item 'How important it is for healthcare professionals to be involved in tobacco control activities' was significantly different by place of work $[\mathrm{H}(2)=9.07$; adjusted $\mathrm{p}<0.001]$. Subsequent Dunn's pairwise tests, with adjustment using the Bonferroni correction, showed that those working in hospital (mean $4.58 \pm 0.56$; adjusted $\mathrm{p}=0.032$ ) and primary healthcare settings (mean $4.67 \pm 0.48$, adjusted $\mathrm{p}=0.014$ ) rated this item as more important than those in residential settings (mean $4.00 \pm 1.03$ ).

\section{Previous tobacco cessation training}

Compared to professionals who had received training in smoking cessation within the past 24 months, those who had not, were less likely to review barriers to quitting amongst those who were unwilling to quit ( $\mathrm{OR}=0.18$; 95\% CI: $0.05-0.73 ; \mathrm{p}=0.016)$.

\section{Non-significant differences}

No significant differences were noted by month of training. Also, differences by participants' highest qualification or location of training were no longer significant following multivariate analyses (Supplementary file, Tables S1-S3).

\section{DISCUSSION}

\section{Reflection on main findings and highlights from the literature}

The inconsistent delivery of all of the 5As was acknowledged in international literature ${ }^{24-28}$. A similar trend in the delivery of the 5As was reported in a study amongst hospital health workers in Catalonia, Spain ${ }^{26}$. Where the acceptable performance of the 5 As was defined as a mean value $\geq 5$, professionals reportedly asked $(6.4 \pm 3.1)$, advised $(7.1 \pm 2.7)$, and assessed $(6.3 \pm 2.8)$ patients for cessation, but few provided assistance $(4.4 \pm 2.9)$, and arranged follow-up (3.2 \pm $3.3)^{26}$. Most probably, healthcare professionals tend to 'assist' and 'arrange follow-up' only to those who are interested in quitting. Nevertheless, guidelines recommend the delivery of all the 5As, irrespective of whether smokers are motivated to quit or not ${ }^{6}$.

Unlike what was reported in some studies ${ }^{24,26-28}$, doctors in our study did not outperform the other healthcare professionals in all the 5As. Nonetheless, doctors were more likely to have counselled an increased number of patients, than other professionals during the previous week. Doctors, being very much involved in the assessment and diagnosis of health interactions, may be more likely to tie in smoking cessation advice in their management.

Although females were more likely to report having sufficient time for counselling, they were less active in advice-giving. Similarly, in the Girvalaki et al. ${ }^{16}$ study, male general practitioners were significantly more likely to 'advise' patients (adjusted odds ratio, AOR $=2.88$; 95\% CI: $1.06-$ $7.86 ; \mathrm{p}<0.05)^{16}$. In contrast, this difference was not observed in the Martinez et al. ${ }^{26}$ study. Also, no significant differences in the delivery of brief interventions were noted by years of experience ${ }^{26}$. However, one must note that unlike our study, almost all participants $(80.8 \%)$ had previous tobacco cessation training ${ }^{26}$. Training, which is known to have a positive impact on delivery of the $5 \mathrm{As}^{29-}$ ${ }^{31}$, could have impacted on the above-mentioned results, eliminating differences by gender and years of experience. Although in our study professionals with more years of experience were more likely to see smoking cessation counselling as an inefficient use of their time, it could be that they had other nonclinical roles such as in management.

Unlike in some international studies ${ }^{24-26}$, delivery of the 5As was not found to be significant by smoking status (Supplementary file, Table S1), probably due to the small number of participating smokers. Nonetheless, as was found in the Yan et al. ${ }^{25}$ study 
(where mean attitudes were: never smokers 18.2 \pm 1.8 versus ever smokers $16.1 \pm 2.7 ; \mathrm{p}<0.05$ ), never smokers were more likely to agree to positive statements towards counselling.

When compared to previous studies, where it was also agreed that smoking cessation is an important professional responsibility ${ }^{24,26}$, and that healthcare professionals should be role models ${ }^{25}$, and be involved in tobacco control activities ${ }^{25}$, our study provided a wider understanding of the participants' opinions and attitudes towards tobacco cessation. Few healthcare professionals, nurses, and allied healthcare professionals in particular, agreed that 'asking' patients increases the likelihood that they will quit. This highlights the participants' lack of knowledge in this evidence-based practice ${ }^{13}$. Health providers working in residential care settings reported less frequent tobacco cessation interventions and fewer positive opinions and attitudes of such role. Probably they perceived little or no benefits for the elderly clients.

Although most participants tended to agree that they had insufficient time to counsel patients, allied healthcare professionals were less likely to. While this is encouraging, as it suggests that allied healthcare professionals might be in a better position to deliver smoking cessation interventions; lack of sufficient time deserves its due attention. Given the benefits of opportunistic brief smoking cessation advice, it is recommended that healthcare management addresses this perceived organisational barrier.

As was found in international literature ${ }^{26,32}$, almost all participants expressed the need for training in smoking cessation. Training healthcare professionals in smoking cessation is more likely to result in positive changes in the delivery of the $5 \mathrm{As}$, such as: asking patients to set a quit date $(\mathrm{p}<0.0001)$; providing follow-up appointments $(\mathrm{p}<0.00001)$; counselling smokers $(\mathrm{p}<0.00001)$; providing selfhelp material $(\mathrm{p}<0.0001)$; and prescribing a quit date $(p<0.00001)^{31}$. All health workers, including allied healthcare professionals, should be provided with training opportunities on tobacco cessation interventions. Given the limited time in carrying out cessation practices, training sessions can help equip professionals with the required skills to deliver interventions, which are brief yet effective. Such initiatives can support professionals who feel that it is difficult for them to help smokers quit and provide skills for addressing barriers. Training should also provide an overview of local community services, especially for those professionals who may be less aware of available services. Moreover, in view of the highlighted benefits of opportunistic smoking cessation amongst older adults ${ }^{33}$, training initiatives should be also provided to professionals working in residential care settings. In addition, given that former smokers were more confident in helping patients quit, engaging their experiences within any training activities would be an asset.

National clinical guidelines or protocols, which have been found to improve the provision of brief cessation interventions ${ }^{34}$, can also guide professionals to fully engage in the $5 \mathrm{As}$ evidencebased framework. Given that smoking was found to be a risk factor for disease progression of coronavirus disease, COVID-19 $9^{35,36}, 29.8 \%$ of smokers compared with $17.5 \%$ of non-smokers experienced disease progression $(\mathrm{OR}=1.91 ; 95 \%$ CI: $1.42-2.59$; $\mathrm{p}=0.001)^{36}$, the rapid increase of which has made the WHO European Region the centre of this pandemic, promoting use of brief tobacco cessation interventions through training efforts and issuing of protocols/guidelines would be of further significance for the current times.

\section{Strengths and limitations}

This is the first time that the extensively used tool by Sarna and Bialous et al. ${ }^{18}$ has been used amongst a wide array of healthcare professionals, not only providing a detailed description of practices, opinions and attitudes, but also identifying differences by professional characteristics. There are some limitations. Our survey was completed by a small number of healthcare professionals, working in Malta, who attended a training session. These participants may have been more likely to engage in tobacco cessation interventions than those who did not participate, limiting the generalizability of the findings to the total healthcare population. A largerscale study in another European country is thus recommended. Notwithstanding the small sample size, the training sessions were carried out in four different settings, using different recruitment strategies to encourage participation, and including a wide array 
of participating healthcare professionals (except for pharmacists) to enable comparison between groups of professionals. No oral healthcare professionals participated in this study, however various other studies have included these professionals ${ }^{24,27,28}$. As the data on the delivery of tobacco cessation interventions were self-reported, the results may not be an accurate assessment of the actual interventions. There might have been other factors, other than those studied that could have influenced the results presented. Nonetheless, multivariate analyses were conducted, ruling out identified confounders.

\section{CONCLUSIONS}

In line with international literature, the inconsistent delivery of all the 5As was also reported in our study. While the majority asked their patients about tobacco use, advised those who smoke to quit and assessed patients' interest in smoking cessation, few participants provided assistance and arranged followup appointments. Compared to other participants, doctors were more likely to have counselled patients over the previous week. Most professionals were favourably disposed towards counselling patients to quit, yet most claimed they had insufficient time to counsel patients. Also, while most participants found that it is difficult for them to get people to quit, healthcare professionals who were former smokers were more likely to disagree. Those working in residential care settings reported less frequent tobacco cessation interventions and had fewer positive opinions and attitudes of such a role. Nonetheless, almost all participants agreed that they needed more training to help patients to quit smoking.

Training initiatives on brief smoking cessation interventions should be held for all healthcare professionals, potentially featuring the advice usually provided by healthcare professionals who were former smokers. It is also recommended that management addresses the perceived time barrier, for increased delivery of brief tobacco cessation interventions.

\section{REFERENCES}

1. World Health Organization. WHO Global Report on Trends in Prevalence of Tobacco Smoking 2000-2025. Geneva, Switzerland: World Health Organisation; 2018. https://apps.who.int/iris/bitstream/hand le/10665/272694/9789241514170-eng.pdf?ua $=1$. Accessed June 30, 2020.

2. European Union. Special Eurobarometer 429: Attitudes of Europeans towards Tobacco and Electronic Cigarettes. https://ec.europa.eu/commfrontoffice/publicopinion/ archives/ebs/ebs_429_en.pdf. Published 2015. Accessed June 30, 2020.

3. World Health Organization. WHO report on the global tobacco epidemic 2019: Offer help to quit tobacco use. https://www.who.int/tobacco/global_report/en/. Published July 26, 2019. Accessed June 30, 2020.

4. Godtfredsen NS, Holst C, Prescott E, Vestbo J, Osler M. Smoking reduction, smoking cessation, and mortality: A 16-year follow-up of 19,732 men and women from the Copenhagen Centre for Prospective Population Studies. Am J Epidemiol. 2002;156(11):994-1001. doi:10.1093/aje/kwf150

5. World Health Organization. WHO Framework Convention on Tobacco Control. Geneva, Switzerland: World Health Organization; 2003. https://www.who.int/tobacco/ framework/WHO_FCTG_english.pdf?ua=1. Accessed June 30, 2020.

6. European Network for Smoking and Tobacco Prevention. 2018 Guidelines for Treating Tobacco Dependence. http://elearning-ensp.eu/pluginfile.php/1052/mod_ resource/content/2/guidelines_2018_english.pdf. Published 2018. Accessed June 30, 2020.

7. Sartorius N, Haghir H, Mokhber N, et al. The ICD-10 Classification of Mental and Behavioural Disorders. IACAPAP E-textb child Adolesc Ment Heal. 2013;55(1993):135-139. doi:10.4103/0019

8. American Psychiatric Association. Diagnostic and Statistical Manual of Mental Disorders. Washington, DC: American Psychiatric Association; 1980.

9. Xiao D, Wang C. Tobacco dependence should be recognised as a lethal non-communicable disease. BMJ. 2019;365(May):10-12. doi:10.1136/bmj.12204

10. World Health Organization. Toolkit for Delivering the 5A's and 5R's Brief Tobacco Interventions in Primary Care. Geneva, Switzerland: World Health Organisation; 2014. https://www.who.int/tobacco/publications/ smoking_cessation/9789241506953/en/. Accessed June $30,2020$.

11. Kruger J, O'Halloran A, Rosenthal AC, Babb SD, Fiore MC. Receipt of evidence-based brief cessation interventions by health professionals and use of cessation assisted treatments among current adult cigarette-only smokers: National Adult Tobacco Survey, 2009-2010. BMC Public Health. 2016;16(1):1-10. doi:10.1186/s12889-016-2798-2

12. Conroy MB, Majchrzak NE, Regan S, Silverman CB, Schneider LI, Rigotti NA. The association between patient-reported receipt of tobacco intervention at a primary care visit and smokers' satisfaction with their health care. Nicotine Tob Res. 2005;7(Suppl 1):29-34. doi:10.1080/14622200500078063

13. Çakir B, Taş A, Şanver TM, Aslan D. Doctor's enquiry: 
An opportunity for promoting smoking cessation - Findings from Global Adult Tobacco Surveys in Europe. Eur J Public Health. 2017;27(5):921-925. doi:10.1093/eurpub/ckx094

14. Schauer GL, Wheaton AG, Malarcher AM, Croft JB. Health-care provider screening and advice for smoking cessation among smokers with and without COPD 2009-2010 national adult tobacco survey. Chest. 2016;149(3):676-684. doi:10.1378/chest.14-2965

15. Kennedy RD, Behm I, Craig L, et al. Smoking cessation interventions from health care providers before and after the national smoke-free law in France. Eur J Public Health. 2012;22(Suppl 1):23-28. doi:10.1093/eurpub/ckr209

16. Girvalaki C, Papadakis S, Vardavas C, et al. Smoking cessation delivery by general practitioners in Crete, Greece. Eur J Public Health. 2018;28(3):542-547. doi:10.1093/eurpub/ckx201

17. World Health Organization. European Tobacco Use, Trends Report 2019. https://www.euro.who.int/_data/ assets/pdf_file/0009/402777/Tobacco-Trends-ReportENG-WEB.pdf. Published 2019. Accessed June 30, 2020.

18. Bialous SA, Sarna L, Wells MJ, et al. Impact of Online Education on Nurses' Delivery of Smoking Cessation Interventions With Implications for EvidenceBased Practice. Worldviews Evidence-Based Nurs. 2017;14(5):367-376. doi:10.1111/wvn.12197

19. Sarna LP, Brown JK, Lillington L, Rose M, Wewers ME, Brecht ML. Tobacco interventions by oncology nurses in clinical practice: Report from a national survey. Cancer. 2000;89(4):881-889. PMID:10951353.

20. Sarna LP, Bialous SA, Králíková E, et al. Tobacco cessation practices and attitudes among nurses in the Czech Republic. Cancer Nurs. 2015;38(6):E22-E29. doi:10.1097/NCC.0000000000000222

21. Ministry for Justice Culture and Local Government. Public Health Act: To promote and protect health. CAP. 465. http://www.justiceservices.gov.mt/DownloadDocument. aspx?app=lom\&itemid=8931. Published November 21, 2003. Accessed June 30, 2020.

22. Ministry for Justice Culture and Local Government. DATA PROTECTION ACT: AN ACT to repeal and to replace the Data Protection Act, Cap. 440. CAP. 586. http://www.justiceservices.gov.mt/DownloadDocument. aspx?app $=$ lom\&itemid $=12839 \& \mathrm{l}=1$. Published May 28, 2018. Accessed June 30, 2020.

23. European Union. Regulation (EU) 2016/679 of 27 April 2016 on the protection of natural persons with regard to the processing of personal data and on the free movement of such data, and repealing Directive 95/46/ EC (General Data Protection Regulation). Off J Eur Union. 2016;59(L119):1-89. http://data.europa.eu/eli/ reg/2016/679/oj. Accessed June 30, 2020.

24. Tong EK, Strouse R, Hall J, Kovac M, Schroeder SA. National survey of U.S. health professionals' smoking prevalence, cessation practices, and beliefs. Nicotine Tob
Res. 2010;12(7):724-733. doi:10.1093/ntr/ntq071

25. Yan J, Xiao S, Ouyang D, Jiang D, He C, Yi S. Smoking behavior, knowledge, attitudes and practice among health care providers in Changsha city, China. Nicotine Tob Res. 2008;10(4):737-744. doi:10.1080/14622200801901930

26. Martínez G, Castellano Y, Andrés A, et al. Factors associated with implementation of the $5 \mathrm{~A}$ 's smoking cessation model. Tob Induc Dis. 2017;15(1):1-12. doi:10.1186/s12971-017-0146-7

27. Sheffer CE, Barone CP, Anders ME. Training health care providers in the treatment of tobacco use and dependence: Preand post-training results. J Eval Clin Pract. 2009;15(4):607613. doi:10.1111/j.1365-2753.2008.01058.x

28. Matouq A, Khader Y, Khader A, et al. Knowledge, attitudes, and behaviors of health professionals towards smoking cessation in primary healthcare settings. Transl Behav Med. 2018;8(6):938-943. doi:10.1093/tbm/ibx045

29. Payne TJ, Gaughf NW, Sutton MJ, et al. The impact of brief tobacco treatment training on practice behaviours, self-efficacy and attitudes among healthcare providers. Int J Clin Pract. 2014;68(7):882-889. doi:10.1111/ijcp.12386

30. Martínez C, Castellano Y, Company A, et al. Impact of an online training program in hospital workers' smoking cessation interventions in Bolivia, Guatemala and Paraguay. Gac Sanit. 2018;32(3):236-243. doi:10.1016/j.gaceta.2017.10.020

31. Carson K, Verbiest M, Crone M, et al. Training health professionals in smoking cessation. Cochrane Database Syst Rev. 2012;(5):CD000214. doi:10.1002/14651858.cd000214

32. Meijer E, van der Kleij R, Segaar D, Chavannes N. Determinants of providing smoking cessation care in five groups of healthcare professionals: A cross-sectional comparison. Patient Educ Couns. 2019;102(6):11401149. doi:10.1016/j.pec.2019.01.015

33. Doolan DM, Froelicher ES. Smoking cessation interventions and older adults. Prog Cardiovasc Nurs. 2008;23(3):119127. doi:10.1111/j.1751-7117.2008.00001.x

34. Hilberink SR, Jacobs JE, de Vries H, Grol RPTM. Smoking cessation counselling in general practice for COPD smokers: determinants for general practitioner's compliance with a treatment protocol. Int J Heal Promot Educ. 2013;51(2):6474. doi:10.1080/14635240.2012.750069

35. European Network for Smoking and Tobacco Prevention. COVID-19 Pandemic and Smoking Behavior: An Elevated Risk and a Golden Opportunity for Quitting. http://ensp. network/wp-content/uploads/2020/04/Factsheet-3.pdf. Published April 16, 2020. Accessed June 30, 2020.

36. Patanavanich R, Glantz SA. Smoking is Associated with COVID-19 Progression: A Meta-Analysis. Nicotine Tob Res. 2020:1-4. doi:10.1093/ntr/ntaa082

37. Ministry for Justice Culture and Local Government. HEALTH CARE PROFESSIONS ACT: To regulate the practice of health care professions in Malta. CAP. 464. http://justiceservices.gov.mt/DownloadDocument. aspx?app $=$ lom \&itemid $=8930 \& \mathrm{l}=1$. Published November 
21, 2003. Accessed June 30, 2020.

38. Ministry for Health. Allied Health Care Services - About Us. https://deputyprimeminister.gov.mt/en/ahcs/Pages/ Overview.aspx. Updated 2020. Accessed December 30, 2019.

CONFLICTS OF INTEREST

The authors have completed and submitted the ICMJE Form for Disclosure of Potential Conflicts of Interest and none was reported.

FUNDING

There was no source of funding for this research.

PROVENANCE AND PEER REVIEW

Not commissioned; externally peer reviewed. 